Recibido: $18 / 03 / 2015$

Aceptado: 20/05/2015

\title{
LAS COMUNIDADES NO CONFEDERADAS DE CANÓNIGOS REGULARES EN CATALUÑA EN LA BAJA EDAD MEDIA*
}

\author{
NOT CONFEDERATE COMMUNITIES OF REGULAR CANONS \\ IN CATALONIA IN THE LATE MIDDLE AGE
}

\author{
José Antonio Calvo Gómez \\ Instituto Español de Historia Eclesiástica. Roma \\ Universidad Católica de Ávila (UCAV)
}

\begin{abstract}
Resumen: Este trabajo de investigación pretende determinar la extensión real de las comunidades de canónigos regulares en Cataluña que no se vincularon a ninguna de las grandes Órdenes radicadas después del siglo XI. Frente a un modelo explicativo que despreciaba, por residuales, las comunidades adheridas a la Regla de san Agustín, pero ajenas a las congregaciones internacionales, este trabajo muestra un fenómeno verdaderamente generalizado, fundamental en la repoblación de algunos territorios de la Corona de Aragón, que se prolongó, con cierta vitalidad, hasta final de la Edad Media.
\end{abstract}

Palabras clave: Reforma Gregoriana, canónigos regulares, siglo XI, repoblación, Cataluña.

\begin{abstract}
This study tries to determine the real extension of the communities of regular canons in Catalonia not vinculated to any religius Ordo founded in this territory after the 11th century. Againts an model that despised the communities of canons of Saint Augustine outside the international congregations, this work shows a widespread phenomenon, essential in the repopulation of some territories of the Crown of Aragon, which lasted, with vitality, until the end of the Middle Ages.
\end{abstract}

Keywords: Gregorian reform, regular canons, 11th century, repopulation, Catalonia.

* Este trabajo ha sido realizado con la ayuda del Centro Español de Estudios Eclesiásticos anejo a la Iglesia Nacional Española de Santiago y Montserrat en Roma en el marco de los proyectos de investigación del curso 2013-2014. 


\section{Introducción}

Algunas de las congregaciones más importantes de canónigos regulares, surgidas en Centroeuropa y en el Próximo Oriente en el contexto de la Reforma Gregoriana a lo largo de los siglos XI y XII, se implantaron con cierta rapidez en los territorios de la Corona de Aragón que, en la lucha por la hegemonía contra el Islam, iban siendo integrados, paulatinamente, en el espacio jurisdiccional de los reinos cristianos (Álvarez Gómez, 1989: 46-50). ${ }^{1}$

Las cuatro congregaciones con una presencia más relevante en la Península Ibérica durante los siglos XII y XIII fueron las de San Rufo de Aviñón, el Santo Sepulcro de Jerusalén, los canónigos de Premostré y los canónigos regulares del hábito de San Antonio de Vienne. Las comunidades regulares de la obediencia de San Rufo y del Santo Sepulcro de Jerusalén se establecieron predominantemente en los territorios de la Corona de Aragón. Las primeras casas de los canónigos Aviñonenses fueron catalanas. Los sepulcristas, por su parte, iniciaron su presencia peninsular en torno a la casa de Calatayud al tiempo que, los canónigos de Premostré y los del hábito de San Antonio Abad alcanzaron pronto todos los territorios hispánicos.

En estas cuatro congregaciones de canónigos y los respectivos monasterios regulares hispánicos, en correspondencia con los ubicados en los territorios europeos y del próximo Oriente medieval, se puede establecer un cierto programa ordenado, coherente, que permite crear un modelo interpretativo lógico, en el que se anota su definido itinerario fundacional, las líneas maestras de su evolución histórica posterior y la extensión institucional. Sin embargo, frente a todo este esquema, las distintas comunidades regulares no confederadas escaparon continuamente de cualquier ordenamiento y, en muchas ocasiones, de cualquier historia comunitaria que las ligara a un proyecto superior, que intentamos delimitar en este trabajo.

Los territorios hispánicos en la baja Edad Media acogieron pronto las inspiraciones de san Agustín para la vida común del clero. Pero la materialización histórica de esta intuición distó mucho de ser uniforme (Constable,

1 Para un conocimiento global del problema de los canónigos regulares en la Edad Media, de la Reforma Gregoriana en la Península Ibérica, y del surgimiento de los canónigos regulares, por orden cronológico, vid. Dereine, 1946: 362- 406; ID., 1947: 352- 378; ID., 1951: 534- 565; ID., 1961: 108- 118; ID., 1971: 383; Giroud, 1961; VVAA., 2006; Parisse, 2009; García de Cortázar, - Teja Casuso 2009; Calleja 2009; Álvarez de las Asturias, 2011; así como los congresos celebrados en La Mendola, Italia, en 1961, publicado en Milán el año siguiente: y en Zaragoza, en 1991. Vid. VVAA., 1962; VVAA., 1991. 
1982: 349-389). ${ }^{2}$ Después del siglo XI, muchas comunidades peninsulares, sin adscripción a ningún Orden superior, más allá de la obediencia debida al prelado diocesano o directamente al papa, recurrieron a la Regla fundamentalmente para legitimar su vinculación con la vida regular, sin que este hecho representara inicialmente ninguna valoración de su adhesión a los proyectos de los protagonistas de la Reforma Gregoriana (Sastre, 1983: 251-314).

La rica variación de realidades institucionales complica el agotamiento del modelo peninsular que incluyó canónigos cuya vida se asemejó a la de los eremitas del desierto egipcio, canónigos hospitalarios, y clérigos parroquiales, hasta quienes, en el marco de una misma existencia agustiniana, se asemejaron notablemente a los canónigos seculares de las catedrales medievales hispánicas. En ocasiones, observamos que algunas comunidades sacerdotales bajomedievales adoptaron durante un tiempo la vida regular agustiniana, que depusieron pronto cuando este modelo institucional les impidió el ejercicio de su propia idiosincrasia.

Sin una vinculación a una congregación superior, la permanencia en una forma de vida comunitaria estricta se hizo más difícil y la variación que se observa, después de algunos años de vida más rigurosa en los principios de la Regla, condujo, casi con carácter general, sobre todo a partir de mediados del siglo XIV, a una estructura más parecida a la de los clérigos parroquiales, por un lado, o a la de los canónigos seculares de las colegiatas y catedrales de los distintos territorios de la Corona de Aragón, por otro, cuando no a una confluencia de ambas obediencias, como la que se dio en el caso de las colegiatas que rigieron diferentes iglesias parroquiales a ellas encomendadas (Gómez Santos, 1971: 301- 316).

Por otro lado, la documentación resulta más escasa precisamente en aquellos momentos en los que la vida comunitaria regular fue más estricta. En los primeros tiempos, las prioridades diplomáticas pasaban, generalmente, a un segundo plano, relegadas por una sincera búsqueda de la reforma de la Iglesia. La necesidad de afirmar los derechos de la comunidad,

2 En esta aportación, el profesor Gilles Constable establece las líneas maestras de lo que considera el modelo apostólico de la Iglesia altomedieval, modificado fundamentalmente con la reforma que se inicia con el papa León IX a mediados del siglo XI. La pervivencia de ciertas estructuras de evangelización del mundo rural, a través del pensamiento agustiniano de la vita vere apostolica, tiene en los cabildos de canónigos regulares su mejor exponente. 
frente a reivindicaciones jurisdiccionales y económicas externas, eclesiales o civiles, hizo más necesario, generalmente, compilar los diplomas correspondientes que legitimaran determinadas situaciones. Este sesgo puede distorsionar en parte el conocimiento que tengamos de las comunidades regulares aragonesas no ordenadas por una congregación canónica y matizar indebidamente todo cuando podamos decir sobre ellas a partir de este momento.

Este hecho, por tanto, introduce un factor de provisionalidad en todo lo que se indique, con carácter general, de la vida regular hispánica. Las confusiones terminológicas, además, están presentes en numerosas publicaciones contemporáneas sobre este fenómeno eclesial (García de Cortázar - Teja, 2009). La solución a esta paradoja puede encontrarse fundamentalmente en el conocimiento monográfico que llegue a alcanzarse de cada comunidad, del protagonismo de sus fundadores, muchas veces desconocidos, de su itinerario institucional, de las relaciones que llegaron a establecer con otras realidades de Iglesia y de la sociedad civil, de su economía y de una buena serie de factores que, en este trabajo, particularizado para cada comunidad canónica regular, resultaría insensato siquiera plantear.

\section{Los canónigos regulares en la Cataluña medieval}

\subsection{Cataluña, tierra canonical}

M. Riu Riu ${ }^{3}$ estudió, entre otros, el modelo regular en la Cataluña medieval. En su obra, singularmente amplia, pormenorizada, diversificada en tiempos y lugares, no sólo del ámbito catalán y aragonés, repasó cómo se llevó a cabo la sustitución de monasterios de tradición benedictina por cabildos agustinianos de canónigos regulares, obedeciendo al espíritu de la época. Este autor señaló que se trató de un fenómeno inverso al que se había producido al advenimiento de la hipertrofia monástica en los primeros siglos de la reconquista, cuando ciertas comunidades de tradición fundamentalmente aquisgranense pasaron a constituir nuevos monasterios y otras, sin perder su condición canónica, se integraron en la dotación de los mismos.

3 La obra sobre el monacato catalán de Manuel Riu Riu, en todas sus formas y manifestaciones, es singularmente amplia. Además de las que citamos en su lugar correspondiente, vid. Riu, 1970-1971: 593- 614; Id., 1988: 85-112. 
E. Zaragoza Pascual (Zaragoza, 1977: 93-203; 1996: 661-721; 1997), en la estela de A. Pladevall i Font (Pladevall, 1974), ${ }^{4}$ ofreció todavía un panorama más amplio y pormenorizado de cuando pueda decirse en torno al fenómeno monástico en todas sus variantes, también en lo que quepa afirmar sobre los monasterios y corporaciones de canónigos regulares de san Agustín en Cataluña. Según este autor, «ya en el siglo VIII hubo comunidades de canónigos en las catedrales, que seguramente seguirían la regla del concilio de Aquisgrán (816) vigente en todo el imperio carolingio. Pero la vida y rentas comunes que establecía el concilio no perduraron por muchos años».

Existió un verdadero intento de renovación de la vida canónica en las catedrales de Barcelona (1009), la Seo de Urgell (1010), Gerona (1019) y Vic (1080). Incluso antes, en el siglo X, surgieron los primeros monasterios episcopales de Urgell, como el de Idona y el de Santa María de Valldeflors de Tremp o de Pallars, ${ }^{5}$ que tuvieron una índole clerical y pastoral (Riu, 19901991: 351-373). San Lorenzo de Morunys o de los Piteus, monasterio benedictino, tuvo por abades a los rectores de las parroquias inmediatas (Riu, 1982: 159-182). Como canónicas surgieron las comunidades clericales de San Pedro de Graudescales (Pladevall, 1974: 39-40; Villanueva, 1850: 30-32; Zaragoza, 1997: 117-118); ${ }^{6}$ San Pedro de Ger, en la Baja Cerdaña: ${ }^{7}$ Santa María de Talló, también en la Baja Cerdaña, diócesis de Urgell (Pladevall, 1974: 37 y 52;

4 Este autor ha publicado también algunas monografías sobre los monasterios catalanes, no todos cabildos de canónigos regulares, y algunas obras de síntesis sobre la Iglesia catalana medieval: Vid. Pladevall., 1994: 181-196; Id., 2001: 59-72; Id., 2002: 145-154.

5 Este monasterio, cuya iglesia ya existía en el año 839 y fue destruida por los árabes en el año 1040, fue generosamente dotado por Ramón V de Pallars y su esposa Valencia de Tost en 1079, cuando se aborda la ampliación y renovación de la iglesia. En 1403, tuvo lugar la tercera consagración de un nuevo templo, sustituido más tarde por el actual, erigido en 1642. Desde 1087, existió una comunidad regular, unida en 1257 a la mesa episcopal de la Seo de Urgell. Después de 1313, el cabildo de rige por unas normas propias, entregadas por el obispo Ramón Trebaylla, benedictino y, desde 1391, se cuentan entre los sacerdotes algunos beneficiados seculares, anticipo de la definitiva secularización del cabildo en el siglo XV, cuando reside un solo canónigo en el lugar con el título de pavorde. Vid. Mir i Amat, 1978; Lledós i Mir, 1977; Pladevall, 1974: 56; Zaragoza, 1997: 226. Existen, de esta colegiata, dos obras clásicas. La del canónigo premonstratense, Pascual, 1785, más amplia, es seguida de cerca por Joaquín Lorenzo Villanueva (1757-1837) para redactar la parte correspondiente a la obra póstuma Viage a las iglesias de España. Vid. Villanueva, 1850: 67-70.

6 Existe, no obstante, cierta discrepancia sobre la adscripción agustiniana de este monasterio. E. Zaragoza indica que, en el año 913, el obispo Nantigís de Urgell consagró la iglesia de una comunidad benedictina, sustituida en el año 960 por un cabildo de canónigos regidos por la Regla de Aquisgrán. Vid. Guerrero, 1971.

7 Sobre su dependencia de la abadía benedictina de San Sadurní de Tavérnoles, vid. Baraut, 1980: 253 259; Zaragoza, 1997: 111-112. 
Zaragoza, 1997: 219); ${ }^{8}$ San Juan de Montdarn, en la Berguedá, entonces diócesis de Urgell, ahora de Solsona (Pladevall, 1974: 25, 52 y 108; Villanueva, 1850: 61-64; Zaragoza, 1997: 150); ${ }^{9}$ Santa María de Lluçá, en la diócesis de Vic (Casades, 1897; Pladevall, 1969; Serra, 1950; Zaragoza, 1997: 134); ${ }^{10}$ San Jaume de Frontañá, entre Ripoll y Puigcerdá, en la Berguedá (Pladevall, 1974: 280-283; Zaragoza, 1997: 108); ${ }^{11}$ Santa María de la Pobla de Lillet, junto al Llobregat, también en la comarca del Berguedá, en la diócesis de Solsona (Baraut, 1978: 11-182; Riu, 1978: 267-290; Zaragoza, 1997: 129); ${ }^{12}$ y San Pedro de Vilamajor, en la comarca barcelonesa del Vallés Occidental (Martí, 1981; Mundó, 1961: 48-67; Pladevall, 1974: 54; Zaragoza, 1997: 246). ${ }^{13}$

La verdadera vida canónica regular, añadió E. Zaragoza, en los siglos X y $\mathrm{XI}$, «hay que buscarla en las grandes abadías de San Feliu de Gerona (Zarago-

8 Sin embargo, indica que este monasterio episcopal, cuya iglesia ya existía en el año 839, fue donado en el año 941 a la abadía de San Lorenzo de Bagá para que instalase allí una comunidad benedictina, que perdurará hasta el siglo XIV.

9 Este monasterio episcopal, erigido en el siglo IX, fue entregado, hacia el año 899, a la jurisdicción de la abadía de San Juan de las Abadesas, donde se trasladó el cabildo de canónigos regulares para sustituir a la abadesa Ingilberga y su comunidad benedictina cuando resultó inadmisible su vida escandalosa. Vid. Danés, 1912.

10 Según E. Zaragoza, este monasterio regular fue erigido junto a una iglesia consagrada en el año 905 por el obispo Idalguer de Vic. Desde principios del siglo XII, en torno a este templo se fueron reuniendo los rectores de las parroquias cercanas y, con el nombramiento del prior Pedro de Sagás (1168- 1185) adoptaron la Regla de san Agustín.

11 Existen dos trabajos específicos sobre este monasterio: Martínez, 1967, con amplia bibliografía; y Vinyeta, 1978. La primera iglesia, según E. Zaragoza, fue consagrada en el año 905, pero en el siglo XI es sustituida por una nueva planta, de estilo románico lombardo, junto a la que se alza el monasterio y un claustro para la comunidad regular. En 1140 era prior regular Ramón Arnau, servido por tres o cuatro canónigos, según el tiempo. Este cabildo, cuyo prior era decano de la comarca del Berguedá, tuvo también jurisdicción sobre las iglesias de Santa Cecilia de Riutort y de Santa Magdalena de Soriguera. Sin embargo, desde el siglo XV el cargo prioral se convierte en comendatario hasta que fue secularizado en 1592 por el papa Clemente VII. En aquel momento, el prior comendador era el obispo de Elna, Francisco Robuster Sala. Desde entonces, este prior fue también canónigo del cabildo de Solsona, recién erigido en sede episcopal.

12 Este monasterio clerical, posiblemente aquisgranense, erigido en torno a una iglesia consagrada en el año 833, fue canónica regular desde, al menos, 1082. En 1220, la comunidad, formada por doce canónigos y un prior, pasa a depender directamente de la Santa Sede. En el siglo XIV, sin embargo, cae en una profunda decadencia que le lleva a perder la parroquia de San Antonio de la Pobla de Lillet en 1356. Sólo al final de esta centuria logra recuperarse parcialmente y, hacia 1397, inicia una amplia renovación de la iglesia parroquial.

13 La iglesia de San Pedro, en el municipio de Vilamajor, está documentada desde la primera mitad del siglo IX. Según E. Zaragoza, en 1108, la parroquia fue donada a la canónica de Barcelona, aunque la comunidad permanece en Vilamajor todavía algunos años más. 
za, 1997: 114), ${ }^{14}$ Santa María de Solsona, ${ }^{15}$ Santa María de Manresa (Benet, 1994; Gasol, 1978; Sarret, 1924), ${ }^{16}$ Santa María de Besalú, ${ }^{17}$ St. Vicenç de Cardona (Pladevall, 1974: 54, 56, 270-275; Serra, 1916; Id., 1954; Zaragoza, 1997: 66), ${ }^{18}$ St. Juan de les Abadesses,${ }^{19}$ St. Miquel de Seu d'Urgell (Corts, 1953), ${ }^{20}$ fundada por el obispo San Ermegol, St. Pere d’Àger (Corredera, 1978; Fite, 1985; Pladevall, 1974: 54, 300-305; Zaragoza, 1997: 13) ${ }^{21}$ y algu-

14 Otros autores han elaborado distintos acercamientos a la problemática que encierra este monasterio de fundación visigoda a las afueras de la ciudad de Gerona. Entre ellos: la obra de Villanueva, 1850: 127-131. Según estas obras, en el año 455, el obispo Rústico, de Narbona, construyó una iglesia sobre el sepulcro del mártir africano, San Félix, situado en una necrópolis pagana y paleocristiana. Junto a ella, pronto se erigió un monasterio donde vivió durante un tiempo el luego obispo gerundense Nonnito (621-633) y que mantuvo la sede catedralicia durante la dominación musulmana, hasta que fuera restaurada la diócesis en el año 785. Desde entonces, hasta 1337, la comunidad del monasterio de San Félix quedó sometida a la catedral de Gerona, con la que formaba un capítulo único, confirmado especialmente después de que el obispo Teotatio (874-888) introdujera en la ciudad la Regla de Aquisgrán en el año 882. Un canónigo de la catedral de Santa María ejercía en San Félix el cargo de abad y muchos canónigos de entre los que vivían en esta comunidad fueron consagrados obispos tanto de la propia sede gerundense como de otras catedrales de la provincia tarraconense.

15 Monasterio de la observancia de San Rufo, secularizado en 1592, sobre el que se erige, al año siguiente, la nueva diócesis catalana.

16 En el siglo IX existía ya una comunidad de sacerdotes en torno a una pequeña iglesia, destruida a principios del siglo X. En el año 940 fue consagrada un nuevo templo, destruido por los musulmanes en 1002. Después de su reconstrucción, en 1098, el obispo de Vic, Berenguer de Lluçà introduce en la comunidad la Regla de san Agustín por medio del prior Bernardo de Santa María de Estany. En el siglo XII fue construida una nueva iglesia románica, antecedente de la iglesia gótica iniciada en 1301 y concluida a finales del siglo XV.

17 Monasterio de la observancia de San Rufo, secularizado en 1592.

18 Esta iglesia estaba servida por clérigos ya en el año 980, pero la poca observancia de la comunidad y la ambición de los vizcondes de la villa habían acabado por arruinarla. En 1019, por intervención del abad Oliva, el vizconde Bernardo de Ausona construyó un nuevo templo, consagrado en 1040, que se convirtió, por su pureza estilística, en modelo para la arquitectura románica catalana. En él se conservaban las reliquias de la Santa Espina y de las santas Valentina y Brígida. Aquí murió en 1240 san Ramón Nonato.

19 Monasterio de la observancia de San Víctor de Marsella y luego de San Rufo de Aviñón, secularizado en 1592.

20 La iglesia, erigida en 1035 por san Ermengol, fue reorganizada en 1122 como cabildo de canónigos regulares de san Agustín. Pero el obispo Gullermo de Montcada lo suprimió y lo unió al capítulo de la catedral. En 1364, el monasterio fue ocupado por una comunidad de dominicos. El obispo san Ermengol, en 1010, reestructuró también la sede catedralicia de Santa María de la Seo de Urgell. Los antiguos canónigos visigodos acogieron pronto la Regla del concilio de Aquisgrán del año 816. Pero en el siglo $\mathrm{X}$ ya no quedaba rastro de vida comunitaria alguna. Tras la restauración en tiempos de san Ermengol, el obispo Folc de Cardona les impuso la Regla de san Agustín, según hizo también en San Vicente de Cardona y en San Jaime de Calaf.

21 En 1035, el conde Ermengol II de Urgell, recuperada la villa de manos musulmanas, funda en la parte alta de la muralla un monasterio benedictino. En 1045, sin embargo, nuevamente conquistado, el cenobio es destruido por las tropas árabes. Dos años después, Arnau Mir de Tost recupera definitivamente la plaza e instala en la iglesia de San Pedro una comunidad de canónigos, a quienes dota con las iglesias 
nas otras». Para evitar al investigador el tedio de leer los hechos particulares de cada canónica, remitimos a la documentación y notas bibliográficas indicadas para cada una, donde, según el interés, pueden localizarse desarrolladas las vicisitudes más relevantes.

\section{2. Canónigos regulares, seculares y monjes benedictinos y cistercienses}

Muchos monasterios catalanes tuvieron su origen en la etapa visigoda y durante la dominación carolingia en la Marca Hispánica altomedieval. Su antigüedad y la variación de sus formas hicieron que, en muchos casos, las fronteras entre la vida regular, los cabildos seculares de clérigos y los monasterios de tradición benedictina no estuvieran tan definidas como permite establecer un estudio más detallado sobre el papel. Los monasterios que cambiaron de adscripción y condición canónica, singularmente en este territorio, no fueron tan excepcionales.

Incluso llegó a producirse la convivencia de canónigos y monjes en un mismo monasterio, como sucedió en Santa María de Meyá (Roig, 1688; Tristany, 1677) ${ }^{22}$ en Vilanova de Meyá, en la diócesis de Urgell, donde cinco canónigos, tres monjes y algunos donados convivieron bajo la misma casa durante el siglo XIII. En otras ocasiones, una canónica podía experimentar un ascenso a cabildo catedralicio y a sede episcopal. La comunidad de Santa María de Solsona, erigida desde antiguo en un extremo del obispado de Urgell, estuvo gobernada por un prior al menos desde el año 923, que se llamará paborde desde principios del siglo siguiente. En 1592, sobre aquella base, fue erigida la diócesis actual de Solsona (Costa, 1959). ${ }^{23}$

de San Salvador y San Vicente de Áger. Por bula de Nicolás II de 1060, esta comunidad fue sometida directamente a la Santa Sede, contra el parecer del obispo de Urgell. En 1066, el propio Arnau ofreció el monasterio a la abadía de Cluny, pero siguió manteniendo su condición canonical, al frete de un territorio que comprendía unas cuarenta parroquias, protegido los condes de Urgell y por los vizcondes de Áger. En 1111, los canónigos aceptan la Regla de san Agustín, que mantienen hasta la secularización de los cabildos regulares por la bula clementina del 22 de agosto de 1592.

22 E. Zaragoza se ha ocupado de ella en varias ocasiones: Zaragoza, 1987: 281-290; Id., 1997: 140-141. Según este autor, paree que este cabildo fue erigido como monasterio familiar a principios del siglo IX y destruido por los musulmanes hacia 1050. Ermengol, arcediano de Barcelona lo convirtió entonces en monasterio agustiniano dúplice. Pero, en 1153 fue recuperado para los monjes de Ripoll. Durante siglos, ostentó la jurisdicción vere nullius sobre doce parroquias, y la civil y criminal sobre treinta y dos pueblos, aunque, después de 1346 fue entregado a los priores comendaticios.

23 También ha llegado hasta hoy la diócesis de Perpiñán, que cae del lado francés, erigida en 1602 sobre la canónica de San Juan que fundara hacia 1102 el conde Guislaberto II del Rosellón con el consenti- 
El monasterio de Santa María de Lavaix, localizado en Pont de Suert, próximo a la confluencia del Noguera Ribagorza y el Gironella, hoy se encuentra sumergido bajo el embalse de Escales, pero su documentación se remonta al siglo IX. Según estos diplomas, el cenobio fue benedictino desde mediados del siglo IX, cabildo de canónigos regulares entre 1091 y 1203 y, luego, cisterciense desde principios del siglo XIII hasta que fuera entregado en encomienda a principios del siglo XVI. El caso, que muestra la complejidad de la vida de una comunidad monástica medieval, fue estudiado con detalle por M. Riu Riu (Riu, 1977) y por I. Puig i Ferreté (Puig, 1984).

El abad Trasvat, dependiente del obispo de Urgell, restauró la comunidad a mediados del siglo IX. En el año 848, muestra de su vitalidad, fundó también el monasterio de San Julián de Sentís, que se integró en su patrimonio, junto a las villas de Massivert y San Vicente de Sas; y, desde el año 947, la iglesia prioral de San Juan de Viu. A principios del siglo XI, este dominio estaba formado por unos 50 lugares, 19 parroquias y los prioratos de Sentís, Viu y San Ginés de Bellerá.

En 1055, el caballero Bertrand, probablemente uno de los compañeros de Arnau Mir de Tost, donó parte del usufructo de una viña a esta casa, por aquel entonces todavía bajo el gobierno de Marqués, el último de sus abades benedictinos. En la escritura de donación, aparecieron el monje Vidal, el presbítero Ramió y el clérigo Pere, que Riu interpretó, aseverando que aquí el monje, el presbítero y el clérigo aparecían más bien como representantes de los monjes, presbíteros y clérigos que hubiese entonces en el cenobio, ya que el documento habló de los «restantes comunitarios» o sirvientes mayores y más jóvenes. Si bien el monje se citó aún en primer término, los residentes en Lavaix que no habían abrazado la regla de san Benito es posible que constituyeran ya un núcleo importante.

En aquella situación, un golpe de fuerza del canónigo de Urgell Raimundo Raimundi no encontró dificultades para ejecutar la substitución. En 1090, poco tiempo después de que el condado de Ribagorza se hubiera incorporado al reino de Aragón y hubiera comenzado en él el reinado de Sancho Ramírez, este noble caballero introdujo en Lavaix la Regla de san Agustín, que mantuvo

miento del obispo de Elna. Conocemos un tercer caso, el del monasterio de San Ginés y San Miguel de Besalú, luego de Santa María, fundado el año 977 por el conde-obispo de Mirón. En 1019, esta canónica se convirtió en la sede de una fugaz diócesis, creada por el conde Bernardo Tellaferro. Vid. Riu, 1979: 211-256. 
durante su abadiato (1090-1118) y luego fue continuada por el ministerio de Berenguer (1140), Pedro de Eroles (1148- 1174) y del abad Bertrán (11851203). Pero no terminaron aquí los avatares de Lavaix pues, en 1223, a petición del obispo de Lérida, Berenguer de Erill, de la familia de los Erill, antigua patrona del monasterio, Honorio III lo incorporó al cenobio cisterciense de Bonafont, autorizando a los comunitarios más reacios al cambio a pasar, si así lo pedían, a la condición de canónigos seculares. ${ }^{24}$

En esta coyuntura se sitúa la historia del monasterio de San Esteban de Bellera, también llamado de San Genil y San Adrián, junto al río Bellera, en el pequeño municipio de Senterada, en la comarca leridana de Pallars Jussá, que sufrió una transformación en concomitancia con el cabildo de Santa María de Lavaix, del que dependió en buena parte de su historia (Pladevall, 1974: 32, 287; Puig, 1984: doc. 55, 62, 77; Villanueva, 1850: 49-51; Zaragoza, 1997: 39-40).

Parece que la iglesia de San Esteban ya existía en el año 792, y que en el año 840 lo regía una comunidad benedictina formada por doce monjes. En el año 936, pasó a la dependencia de Santa María de Gerri por mandato del conde Sunyer de Pallars, pero pronto quedó desierta, sin comunidad, por lo que los condes la vendieron a un particular en 1053. A finales del siglo XI, por influjo de la Reforma Gregoriana, llegaron a San Esteban, procedentes de Santa María de Lavaix, un grupo de canónigos, que iniciaron la vida regular en este lugar, sometidos a la jurisdicción del obispo de Urgell tras su reconocimiento canónico en 1118. En 1076, habían tomado posesión del monasterio de San Julián de Sentís (Villanueva, 1850: 42-43; Zaragoza, 1997: 209), ${ }^{25}$ que había sido fundado en el año 848 por el abad Trasoari de Santa María de Lavaix, probablemente cuando en éste ya no había comunidad. San Esteban tuvo también jurisdicción sobre las iglesias de San Juan del Quiró y Santa María de Sensui, que atendían a través de algunos clérigos seculares a ellos encomendadas.

Desde mediados del siglo XII, dependió directamente de Santa María de Lavaix, que tenía derecho de provisión y visita. Sin embargo, cuando, en 1223, el monasterio de Lavaix fue agregado al Císter, los canónigos que

24 Desde 1123, el monasterio se rige por abades perpetuos cistercienses. Vid. Francino, 2003: 545-562; Gimeno, 1992: 169-192.

25 En la actualidad, apenas queda en pie la iglesia del monasterio, sede de la parroquia de Sentís, en el municipio de Sarroca de Bellera, en la comarca del Alto Ribagorza, diócesis de la Seo de Urgell. 
pretendían mantener la vida regular se trasladaron a Belleda, bajo el gobierno de un prior. En el siglo XIV, sin embargo, esta comunidad fue extinguida y la iglesia monástica quedó sometida a la jurisdicción de Santa María de Lavaix hasta 1835 .

Todavía podemos referir un tercer ejemplo de injerencia de la vida de los canónigos seculares y regulares con los monasterios cistercienses y benedictinos. El monasterio de San Pedro de Clará (Monsalvatje, 1910: 56-60; Pladevall, 1974: 48; Zaragoza, 1997: 77), en el municipio de Orrius, en la comarca del Maresme, surgió por la dotación que hizo Bayó, en el siglo IX, de una iglesia románica que ya existía en el lugar, que pasó, en el siglo X a la dependencia del monasterio benedictino de San Cugat del Vallés, en Barcelona. En 1023, los familiares de Adalets Guadald compraron el templo al conde de Barcelona y lo entregaron a Cluny en 1080, que lo sometió al también monasterio benedictino de San Pedro de Casserres. A su vez, este monasterio erigió en el lugar un cabildo regular que tuvo una existencia efímera. Cuando desaparecieron los canónigos, el monasterio de San Cugat reclamó la iglesia, pero fue adjudicada a Casserres, que colocó allí un prior de su obediencia. Desde 1518, el monasterio fue entregado a priores comendatarios, entre ellos el obispo de Barcelona quien, en 1572, lo unió al Seminario Diocesano, luego al colegio de pobres de Lérida y, en 1597, a la mesa capitular de Solsona, recién erigida. Hoy queda en pie la iglesia gótica construida en los siglos XIII y XIV, que fue abandonada entre 1715 y 1920 después de una profanación.

Se conocen algunos casos parecidos, entre los años 1042 y 1060, estudiados por A. Pladevall, en los monasterios de Santa Grata y Santa María de Senterada (Pladevall, 1974: 32, 54; 1978; 1982), ${ }^{26}$ San Vicente de Oveix o de Insistil (Zaragoza, 1997: 101) y San Pedro de Ager, que fue consolidado por su fundador Arnau Mir de Tost cuando Cluny rehusó una fundación en el lugar, como hemos dejado anotado hace un momento. El monasterio de

26 Existen otros trabajos sobre el monasterio de Santa Grata de Senterada, también llamado de Santa María: Villanueva, 1850: 38-40; Zaragoza, 1997: 208-209. Este cenobio, de origen visigodo, consagrado en honor de santa Grata (santa Engracia), fue restaurado por Poseidón, obispo de Urgell, quien le entregó el eremitorio de San Fructuoso de Balestui y la villa de Serra. Luis del Piadoso, el año 823, y Carlos el Calvo, el 844, confirmaron sus posesiones, siempre dependiente de la mitra de Urgell. En 1042, sin embargo, para aumentar la observancia, el obispo instaló una nueva comunidad de canónigos regulares bajo la advocación de Santa María, que permanecerán en el monasterio hasta principios del siglo XIV, en que fue agregado a la abadía de Santa María de Gerri. 
Santa María de Finestres (Pladevall, 1974: 56, 59; Torrent, 1893; Zaragoza, 1997: 136), en la comarca gerundense de la Garrotxa, fundado por el laico Gormar el año 947, fue benedictino y luego de canónigos regulares. En 1096 era ya un priorato benedictino de San Esteban de Banyoles, confirmado por los decretos de Urbano II de este año, y de Alejandro III del 1175. También conviene hablar del cabildo de San Juan de las Abadesas, monasterio femenino. Ante las continuas situaciones de escándalo, fue convertido en cabildo de canónigos regulares, con la anuencia de Roma, por el conde de Besalú Bernardo Tellaferro. El noble señor de esta villa depuso a la abadesa Ingilberga y redujo a los clérigos sirvientes a la condición de regulares bajo el gobierno de un nuevo abad.

En otros casos, las comunidades regulares fueron transformadas en conventos de la Orden de san Agustín. En el municipio de Viella, en el Valle de Arán, diócesis de Urgell, hubo una iglesia románica destruida en 1938. Este templo, erigido sobre un antiguo santuario pagano, ya existía en 1175. La parroquia de Santa María de Migarán fue ocupada en el siglo XIII por canónigos regulares procedentes de Tolosa de Llenguadoc, que cambiaron su nombre por el de San Agustín de Panyo. A causa de la guerra, los canónigos regresaron a Tolosa y el monasterio fue ocupado por un grupo de ermitaños. En 1506, por influencia del rey Fernando II, los frailes agustinos del convento de Lérida se instalaron en sus dependencias hasta la exclaustración de 1835 en que fue reintegrada a la vida parroquial secular (Zaragoza, 1997: 141-142).

El monasterio de Santa Deota, Santa María y San Pedro de Aneu, en el municipio de Unarre, en el valle de Aneu, diócesis de Urgell, fue benedictino, de canónigos regulares y luego convento de frailes de la Orden de san Agustín (Zaragoza, 1997: 21-22; Pladevall, 1974: 286). En este lugar existió, en tiempo de los visigodos, un templo dedicado a santa Deodata. En el año 839, esta iglesia ya estaba dedicada a Santa María y de ella dependía la de San Juan de Isil, luego monasterio episcopal de clérigos y más tarde de la Orden de San Juan de Jerusalén. En el siglo X, Santa María de Aneu se convirtió en un monasterio de benedictinos y cambió de nuevo su nombre por la advocación de San Pedro. En el siglo XII, sin embargo, pasó a la condición de cabildo de canónigos regulares, que permanecieron allí hasta el siglo XVI, momento en que se introdujo la comunidad de frailes agustinos que lo sirvieron hasta 1771. Queda en pie la iglesia del siglo IX, reconstruida en el siglo XI y modificada en el XVI. 


\section{3. La Reforma Gregoriana y el fortalecimiento de los regulares en Cataluña}

Sin duda, también la gran renovación de la vida canónica catalana tuvo lugar durante el siglo XI por influencia de la Reforma Gregoriana. Después de la casa de Besalú, erigida en 1084, muchas catedrales aceptaron entonces la regla de San Rufo de Aviñón. En Gerona, la vida canónica se expandió por influjo del abad Pedro Rigalt que fundó la comunidad de Santa María de Vilabertán, en el Alto Ampurdán, donde tenía asignada la cura de almas después de la donación particular que recibió de ciertos bienes en el año 1069, con los que construyó una nueva iglesia románica, consagrada en 1100 por el obispo de Gerona (Flórez, 1827: 91, 275-278; Golobardes, 1949; Pladevall, 1974: 157-161; Villanueva, 1850: 28-36, 56, 226; Zaragoza, 1997: 244-245).

En 1080, este cabildo aceptó la Regla de san Agustín y, en 1089, un discípulo de este santo abad la extendió más allá de sus límites monásticos al fundar el nuevo monasterio de Santa María del Campo, en el Rosellón, que nació ya regular, y al reformar el cenobio de San Juan de las Abadesas. El abad Lledó, poco tiempo después, la implantaría en la diócesis de Vic. En el monasterio de Santa María de Vilabertrán, que llegó a controlar once iglesias y los prioratos de Santa María de Olm (Zaragoza, 1997: 164), ${ }^{27}$ en Masarac, en el Alto Ampurdán, Santa María del Campo (Id., 1997: 60-61), en el Rosellón, y los lugares de Delfiá, Vilars y Bac Griella, se conservan todavía los sepulcros del abad Rigalt, muerto en olor de santidad, y de Hortola, notable teólogo de la época. Fue secularizado en 1592 y convertido en colegiata, formada por once canónigos y un arcipreste.

La escasa vitalidad monástica obligó a desviar algunos proyectos fundacionales a la órbita canonical. En 1130, los Vilademany, en su señorío de San Pedro de Cercada (Villanueva, 1850: 210-216; Zaragoza, 1997: 72-73), ${ }^{28}$ en la

27 Esta iglesia, posesión de San Quirze de Colera desde antes del 844, fue cedida a la sede de Gerona que, en 1139, se la entregó al prior de Santa María de Vilabertrán para que erigiera en ella un cabildo de canónigos regulares. Esta comunidad, confirmada por Alejandro III, en 1176, permaneció en Om hasta finales del siglo XIV, en que fue secularizada.

28 De acuerdo a las explicaciones de E. Zaragoza, la iglesia de San Pedro de Cercada fue entregada en 1067 por la familia Vilademany al monasterio benedictino de San Marcial del Montseny para que fundara allí una comunidad monástica. Sin embargo, ante la imposibilidad de llevar a buen término este propósito, el prior Elías del Montseny, conforme con el obispo de Gerona, la entregó, en 1136, a Berenguer de Llavaneres y sus compañeros para que erigieran en ella un cabildo de canónigos regulares bajo la dirección del abad Berenguer de Vilabertrán, en el Alto Ampurdán. La nueva iglesia, considerada por la calidad de su fábrica como la catedral de la comarca de la Selva, fue consagrada en 1245. Favorecida 
comarca de la Selva; y, en 1136, los Vilagelans y Meda en San Llorenç del Munt (Ferrando, 1987; Pladevall-Adell, 1980; Solà, 1964; Vergés, 1871; Zaragoza, 1997: 159-160), en las Guillerías, liberaron sus fundaciones de la dependencia benedictina de San Marcial del Montseny. Se fundaron también entonces los cabildos de San Vicente de Roca (Pladevall, 1974: 59; Zaragoza, 1997: 191-192), ${ }^{29}$ en el municipio gerundense de San Julián de Ramis, en 1187; y el de Santa María de la Oliva, en el pueblo de Vilademuls, en 1197, junto a una iglesia que ya existía desde el siglo $\mathrm{X}$, dependiente hasta entonces del monasterio benedictino de San Esteban de Guialbes, en el mismo municipio gerundense de Vilademuls (Villanueva, 1850: 157, 305-307; Zaragoza, 1997: 163-164). ${ }^{30}$ Estas dos comunidades regulares se encargaron de la reforma de San Martín Sacosta, regida por un presbítero desde finales del siglo IX en la ciudad de Gerona (Monsalvatje, 1909: 197-198; Pladevall, 1974: 59, 157-182; Roig, 1676: 332; Vayreda, 1931: 35; Zaragoza, 1997: 197-198). ${ }^{31}$

J. M. Marqués Planagumá añadió que «hacia los inicios del siglo XIII, el movimiento canonical parece haber tenido en Gerona un influjo positivo sobre la atención a parroquias rurales, sea por tenerlas directamente encomendadas, sea por el derecho que le confirió a los canónigos a nombrar sus titulares. Así la canónica rural de San Pedro Cercada pudo designar los párrocos de los alrededores, entre ellos, los de Santa Coloma de Farners» (Marqués, 2006: 461-683).

por la familia Vilademany, el obispo Guillermo de Peratallada entregó a la comunidad canonical, en 1167, las iglesias de San Martín de Esparra y San Iscle de Olleda, posesiones confirmadas por Inocencio III en 1198.

29 El monasterio de San Vicente fue erigido por el arcediano de Gerona, Ramón, con la anuencia del obispo Ramón Guisall, de Gerona, en 1187. Tuvo cierto esplendor durante el priorato de Pedro (12041250) y Bernardo (1275), en que la comunidad estaba formada por tres canónigos y un beneficiado en el altar de Santa María. En el siglo XIV, sin embargo, decae su vitalidad y se integra en la obediencia de San Martín Sacosta.

30 En 1197, la iglesia de Santa María de las Olivas pasó a manos del obispo de Gerona que la entregó a los canónigos de san Agustín para que erigieran allí un cabido regular sujeto a la mitra. En 1262, sin embargo, pasó a la dependencia de la canónica de Vilabertrán, en la misma diócesis, hasta la supresión del cabildo por bula de Clemente VIII de 1592. En este momento, se integró de nuevo en el patrimonio de la catedral de Gerona, que mantuvo el santuario y reedificó la iglesia entre 1722 y 1723 . Desde el siglo XIX, el templo depende de la parroquia de San Esteban de Guialbes, donde se conservan, de la época medieval, parte de la iglesia y la casa prioral, un capitel historiado de los siglos XI- XII y una bella imagen de Santa María, del siglo XV.

31 En 1045, Ponce, capiscol de la catedral, con motivo del crecimiento de este barrio extramuros de la ciudad, construyó en este lugar una nueva iglesia en la que, en 1152, se intenta fundar un priorato dependiente de San Juan de las Abadesas. En 1164, por fin, Arnau de Montbó, canónigo regular de Santa María de Lledó, instaló un cabildo regular, dependiente del obispo de Gerona, que confirmaba a los superiores propuestos. Este cabildo, durante el siglo XV, tuvo agregado el monasterio de San Vicente de la Roca y sus rentas. 
En cuanto a la relación de las comunidades de canónigos regulares entre ellas, debemos apuntar que, en muchas ocasiones, como estamos comprobando, nos encontramos con el establecimiento de algunos monasterios que surgieron espontáneamente, sin la vinculación a ninguna familia canonical y a veces sin el encuadramiento en ninguna rama doctrinal. Este es el caso de Cardona y Solsona, en el obispado de Urgell, que fundaron en 1090 el priorato de Santa María de Orgañá (Pladevall, 1974: 56; Villanueva, 1850: 55-58; Zaragoza, 1997: 165) $)^{32}$ con los mismos canónigos de la catedral.

El monasterio de Santa María de Valldeflors de Tremp o de Pallars, por el contrario, al ser restaurada su iglesia, en 1079, por el conde Ramón de Pallars, se hizo agustiniano, como el premonstratense de Santa María de Mur en 1098 y luego San Pedro de Ager y su filial de San Miguel de Montmagastre (Pladevall, 1974: 39, 56; Sanahuja, 1961; Villanueva, 1850: 48-49; Zaragoza, 1997: 151-152), ${ }^{33}$ en el término municipal de Artesa de Segre, en la Noguera, diócesis de Urgell. También en Urgell, desde 1099, el obispo san Ota hizo de Guissona un centro de expansión del nuevo género de vida y le entregó la jurisdicción sobre más de cuarenta parroquias. El prior, sin embargo, hasta su secularización en 1272, fue siempre un canónigo de la Seo de Urgell. Después del siglo XV, fue erigida la colegiata de Santa María de Guissona, de la que ha llegado con las reformas del siglo XVIII. Hoy es la parroquia de la villa homónima (Pladevall, 1974: 57; Sangés, 1980: 195- 305; 2006-2007: 171-334; Zaragoza, 1997: 119-120). ${ }^{34}$

En 1065, cuando Pedro Rigalt fundó la casa de Santa María de Vilabertrán, cerca de Figueras, organizó también un movimiento en torno a él, tal vez ini-

32 Este monasterio del Alto Urgell, se levantó junto a una iglesia construida por Isarn, señor de Cabó, por la intervención de su nieto, Isarn Ramón. En 1057, san Ermengol la reedificó y consagró para instalar allí una comunidad benedictina. Pero parece que esta fundación no llegó a consolidarse porque, pocos años después, la iglesia era servida por el clérigo Adalbertí, concubinario y malversador de sus bienes, que fue depuesto en 1090, en una reunión de la familia Isarn y de los priores de los cabildos de Cardona, Solsona y Tresponts, junto al obispo de Urgell. De esta reunión, añade E. Zaragoza, surge una nueva dotación de la iglesia por los esposos Guitern Isarn y Gibellina, y la instalación de una comunidad de canónigos regulares de san Agustín bajo la obediencia del obispo de Urgell, quien nombraría el prior. Entre 1202 y 1224, tiene lugar una lucha prolongada, en la que la comunidad obtiene la independencia de la mitra de Urgell.

33 La iglesia de San Miguel, en Montmagastre, fue erigida en 1011 y agregada al monasterio benedictino de San Sadurní de Tavérnoles. En 1085, fue introducida la vida regular por los canónigos de San Pedro de Áger, por lo que sus abades empezaron a llamarse abad de San Pedro de Áger y Montmagastre. En 1108, este lugar, que tenía unidas las iglesias de Santa María de Vedrenya, San Miguel de Comiols, Santa María de Anya, Santa Cruz y San Juan, era ya un priorato simple de Áger, pero sin comunidad.

34 Sobre la vida de la comunidad de Guissona posteriormente, vid. Llober, 1990: 229-236. 
cialmente bajo la congregación de San Rufo de Aviñón. En 1069, adquirió el título personal de jefe y gobernador y, en 1089, la convirtió en una canónica agustiniana, para adquirir en 1100 el título de abad. El mismo año de 1089 surgió a su vera, pero con independencia jurídica, Santa María de Lledó (Monsalvatje, 1904: 95-109; Pladevall, 1974: 59, 162-164; Vayreda, 1931: 86-87; Zaragoza, 1997: 129-131), ${ }^{35}$ en el municipio gerundense de Lledó d’Empordá, que se encargó desde 1095 de lo que llegaría a ser la prepositura de Santo Tomás de Riudeperes (Pladevall, 1974: 55, 56, 162; Puig, 1918: 267-268; Vayreda, 1931: 88-90; Zaragoza, 1997: 189-190), ${ }^{36}$ en el municipio de Calldetenes, cerca de Vic; y del priorato de Santa María del Vilar, en la diócesis francesa de Elna. En 1090 el mismo Rigalt fundó Santa María del Campo, también en Rosellón; y hacia 1093 se hizo cargo de San Juan de las Abadesas, en continuo conflicto con los benedictinos de San Víctor de Marsella.

En 1083, el canónigo Amado firmó el acta de consagración de la iglesia del monasterio benedictino de Santa María de Castellfollit de Riubergós, donde más tarde surgió el priorato también benedictino de San Benet del Bagés. Cuatro años después, otro abad, Alberto, estuvo presente cuando el obispo de Vic, Berenguer Seniofredo de Lluçá, dio a sus canónigos una regla propia. Este obispo, luego metropolitano de Tarragona, creó una obra lo suficientemente densa como para que Antonio Pladevall la considere como otro gran movimiento de reforma, junto a la agustiniana y a la de Aviñón.

35 El monasterio de Santa María de Lledó, fundado por los señores de Navata en 1089, fue entregado casi inmediatamente al obispo de Gerona para que erigiera en el lugar un cabildo de canónigos regulares de san Agustín. Entre los primeros clérigos de monasterio aparece Arnau, hijo de los mismos señores de Navata, que ya era canónigo en Gerona y luego fue obispo de Carcassona. Según E. Zaragoza, el primer prior de Lledó, Juan, procedente de Vilabertrán, fue el encargado de organizar cierto patrimonio, que lleva a la aprobación pontificia en 1124 de la mano del papa Calixto II. En 1171, el rey Alfonso I de Aragón da licencia al monasterio para que amplíe su fábrica, y Jaime II le entrega la jurisdicción civil sobre el priorato de Santa María del Vilar, que tenía anexo. Su patrimonio se extendía por las diócesis de Elna, en Francia, Vic y Gerona; y su iglesia, consagrada en 1182, contenía las reliquias de san Lamberto, lo que atraía no pocos peregrinos. La decadencia de este cabildo comenzó en el siglo XV por la injerencia de los señores seculares y, en el siglo XVI se consolidó esta intromisión con el nombramiento de los primeros abades comendatarios.

36 El origen de este monasterio, en la comarca de Osona, está en la iglesia de Santo Tomás de Puig-oriol, regida por clérigos seculares desde principios del siglo XI, que descuidaron su fábrica y la llevaron a la ruina. Los caballeros de Ruideperes y Alta-riba, a finales de siglo, la reconstruyeron y la entregaron al prior de Santa María de Lledó para que erigiera en ella un cenobio de canónigos regulares al frente del que estaría el prepósito que él nombrara. En 1094 fue consagrada, de nuevo, y congregó, durante siglos, un número no excesivamente grande de sacerdotes. En el siglo XIV, sin embargo, cayó en decadencia por la injerencia de los señores laicos, que intentaban apropiarse de sus rentas, lo que obliga al prior de Lledó a unir la prepositura a la iglesia parroquial de San Martín de Riudeperes. 
En 1080 fundó Santa María de 1’Estany, a su vez reformadora en 1098 de la canónica de Manresa; y en 1083 acogió bajo la Regla agustiniana a los canónigos de San Juan de las Abadesas, expulsados de su casa por Ricardo, el legado pontificio y abad de San Víctor de Marsella. Su influencia se extendió también a Santa María de Manlleu, en la comarca de Osona (Pladevall, 1974: 56, 59; Torrent, 1893; Zaragoza, 1997: 136), ${ }^{37}$ cerca de Vic; a Santa María de Lluçá, su pueblo natal; y al cabildo rufoniano San Salvador de Arraona, dentro de Sabadell..$^{38}$

\section{4. Otros cabildos regulares de canónigos en los siglos XI- XIII}

Conforme a las inspiraciones para el clero de la Reforma Gregoriana, la Regla de san Agustín transformó poderosamente el devenir de los cabildos catalanes de los siglos XI, XII y XIII. Junto a los grandes monasterios de San Félix de Gerona, Santa María de Solsona, Santa María de Manresa, Santa María de Besalú, San Vicente de Cardona o San Juan de las Abadesas, están documentados, además de los que ya hemos referido arriba, numerosos pequeños cabildos donde floreció, al menos durante un tiempo, la forma de vida que había propuesto el sínodo romano de 1059: San Salvador de Orís o de Bellver (Pladevall, 1974: 59, 80; Zaragoza, 1997: 165), en el municipio de San Boi de Llucanés, en la Osona, diócesis de Vic, fue erigido en lo alto de la montaña de Bellver en 1110 por el prior Pedro Amat y unido en 1411 a la catedral de Vic.

37 La iglesia de Manlleu fue consagrada en el año 906 y reconstruida por Berenguer Seniofredo de Lluçá, obispo de Vic, en 1086. Desde 1102 es la sede de la comunidad regular, según confirma el segundo prior, Arnau, en 1105. En 1131, este cabildo fundó el monasterio de Santa María de Piugpardines, en el valle de Bas, diócesis de Gerona, en la iglesia que le había cedido el obispo de Gerona Bernardo Humberto en 1108. Ese mismo año, el vizconde de Bas, Pedro de Cervera, entrega al cabildo de su jurisdicción la iglesia de San Privat de Bas. El prior de Manlleu mantuvo en Bas una comunidad regular hasta que, en el siglo XIII recuperó el título de prior y puso, para servir esta iglesia, un clérigo secular de la obediencia del obispo de Gerona. Desde 1592, la Iglesia de Santa María de Piugpardines quedó como parroquia secular, hasta la actualidad. Vid. Monsalvatje, 1983: 28, 122. La comunidad de Manlleu, sin embargo, no perdió vitalidad. En su patrimonio, se cuentan también las iglesias de San Esteban de Vila-setrú, San Martín de Sobremunt y San Martín de Sescorts.

38 La primera casa aviñonesa en Cataluña fue la de Santa María de Besalú, cerca del castillo condal, donada en 1084 por el conde Bernardo II, aunque no se consolidó hasta 1111, cuando el obispo de Gerona y el conde de Barcelona lo ratificaron, a pesar de la oposición de algunos canónigos aquisgraneses que subsistían en Besalú. En 1086 sube a la sede de Barcelona el canónigo aviñonense Bertrán y en 1092 funda el priorato de San Rufiano en la iglesia de San Adrián de Besós, que acabó trasladándose a San Adrián, en Santa María de Tarrasa y haciéndose cargo de las iglesias visigóticas de la ciudad. Este monasterio de San Adrián tenía como abad al luego santo Olegario, que llegaría a ser abad del mismo San Rufo de Aviñón y luego obispo de Barcelona y metropolitano de Tarragona. Por su influencia, el papa Lucio II, también canónigo regular, impuso en 1144 la regla de San Rufo en San Juan de las Abadesas. 
San Pedro de Ponts (Pladevall, 1974: 59; Zaragoza, 1997: 165), erigido en el castillo del mismo nombre en la Noguera, diócesis de Urgell, fue dotado por Ermengol, conde de Urgell, en 1143, para que se erigiera en ella un monasterio benedictino que, sin embargo, por mediación del obispo de Urgell, en 1169 ya había sido sustituido por un prior y cinco canónigos regulares. Este cabildo fue secularizado en el siglo XIV cuando las condiciones canónicas se volvieron más adversas.

El monasterio de Santa María de Roca Rossa (Monsalvatje, 1904: 119135; Villanueva, 1850: 156; Zaragoza, 1997: 227-228), en el término de Hostalric, en La Selva, diócesis de Gerona, según la tradición, fue erigido en el lugar que se conserva la memoria de la aparición de la Virgen a una pastora, donde, según algunos autores, Ramón Gausil construyó una capilla y se la entregó a los ermitaños. En realidad, parece que el cenobio fue construido gracias a la donación que, en 1145, hizo Gerardo de Cabrera, vizconde de Gerona y de Urgell, a Bernardo, con el permiso del obispo de Gerona y de los abades de Vilabertrán y San Félix de Gerona, para que erigiera un cabildo de canónigos regulares de san Agustín junto a una iglesia dedicada a santa María. Durante años, este cabildo fue favorecido por los señores de Palafolls, pero luego cayó en encomienda hasta que, en 1592, Clemente VIII lo unió al capítulo de la nueva sede de Solsona.

Santa María de Ullá (Monsalvatje, 1904: 391-399; Pons, 1984; Villanueva, 1850: 86, 88, 241; Zaragoza, 1997: 192-193), en el Bajo Ampurdán, bajo la dependencia del obispo de Gerona, fue erigido por Pedro Vidal en 1121 al pie del castillo de Santa Catalina, en Torroella de Montgrí. Pero las crecidas del río Ter afectaron grandemente a la fábrica y se construyó un nuevo templo sobre el anterior, consagrado en 1182. Bajo su jurisdicción estuvieron las iglesias de Bellcaire, Canet, Canavalls, Llaviá y Fontanilles. Después de años de un cierto esplendor, fue entregada en encomienda hasta que, en 1592, fue secularizada por la bula de Clemente VIII.

\subsection{La decadencia canonical en el siglo XIV y la supresión de 1592}

Los monasterios catalanes llegaron al siglo XIV marcados por las frecuentes fluctuaciones en lo que a la economía y a la observancia de la Regla se refiere. Para entonces, las circunstancias cambiaron, en general, hacia una verdadera descomposición comunitaria marcada por la agresión de las pestes de mediados del siglo XIV, que diezmaron los cabildos, la injerencia de los 
señores laicos, y la plaga de los priores y abades comendatarios, que esquilmaron su economía, usufructuaron las rentas y redujeron la fábrica y la comunidad a niveles de mera subsistencia. Los edificios sufrieron las primeras embestidas del tiempo a finales del siglo XIV y algunos terminaron con graves derrumbes durante el siglo XV y las primeras décadas del XVI. Para entonces, el culto divino y el sustento diario de los cabildos habían experimentado los peores momentos de su historia, lo que complicó sin duda la sustitución de las vacantes (Benito, 2004: 3-30).

E. Zaragoza dibuja un cuadro singularmente ennegrecido a finales del siglo XVI, en que «muchas abadías y algunos prioratos poseían hermosas iglesias y claustros, pero pocas rentas y pocas canónigos» (Zaragoza, 1996: 664). Entre las siete abadías que restaban (Cardona, Ager, Solsona, Estany, Perpiñán, Vilabretrán y San Juan de las Abadesas) apenas contaban con 75 canónigos. Los prioratos, unos 20 a finales del siglo XVI, ${ }^{39}$ podían contar con un único canónigo encargado del culto, a veces con escaso celo por la vida apostólica.

Según la visita que mandó hacer Felipe II para remediar esta situación, los canónigos regulares de Cataluña «no constituían provincia monástica alguna, ni tenían capítulos provinciales, ni visitadores; salían de los monasterios sin licencia de nadie; tenían criadas para su servicio; dejaban entrar mujeres en el claustro; disponían de sus rentas a voluntad -aunque para salvar el voto de pobreza el Jueves Santo y antes de morir entregaban sus llaves al abad o prior-; no daban cuentas a nadie de su administración; no cumplían con sus obligaciones litúrgicas y con las misas fundacionales; no seleccionaban los novicios ni les instruían sobre la Regla y vida canónica; como hábito llevaban sólo un roquete sobre la sotana, que a veces era de seda; traían armas; no tenían capítulo de culpas ni leían la Regla en comunidad y muchos no sabían si leer ni escribir; además asistían a bailes y espectáculos; no guardaban bien las escrituras; sus sacristías e iglesias no tenían suficientes ornamentos ni... limpieza, y algunos estaban inculpados de gravísimos crímenes» (Zaragoza, 1996: 665).

39 Santa Ana de Barcelona, San Pedro de Clarà, Santa María de Lluçá, San Cornelio de Bas, San Pedro de Cercada, San Miquel de Monsmagastre, San Saldoni y Ermenter de Cellers, San Jaime de Frontanyà, Santa María de Besalú, Santa María de Cornellà de Conflent, Santa María de Lledó, Santa María de los Olivos, Santa María de Ullà, Nuestra Señora de la Roca Roja, Santa María de Terrassa, San Jaime de Calaf, San Pedro de Castellnou, San Vicente de Clairá, San Pedro dels Arquells, San Fructuoso de Castellfollit, y la parbodía de Santa María de Manresa, algunos de ellos sujetos a la obediencia de las distintas congregaciones regulares instaladas en este territorio. 
El panorama no era muy alentador, aunque la dureza de sus palabras pudo estar condicionada por la decisión, en 1592, de suprimir los cabildos, que selló Clemente VIII el 22 de agosto, como ya hemos anotado. Todas las abadías y monasterios catalanes de canónigos regulares fueron secularizados. Las abadías se convirtieron en colegiatas, que adscribieron las comunidades y rentas de los prioratos. Sólo Santa María de Solsona fue erigida en catedral, y San Jaime de Frontanyà se unió al Seminario Diocesano de la Seu de Urgell, recién erigido. Hasta 1835, sólo permanecieron los canónigos premonstratenses de Santa María de Bellpuig de las Avellanas. El resto de la vida canonical regular catalana desapareció después de 1592.

\section{Las canónicas en Aragón}

El papel de los canónigos regulares en algunos territorios de Aragón les hizo entrar en competencia con el monacato de origen benedictino al que limitaron en su expansión. Como ocurrió en otros lugares de la vieja Europa, tales avances de la vida canónica tuvieron lugar muchas veces a expensas de los clérigos seculares. Éste es el caso de su implantación en ciertos cabildos catedralicios, como el de Jaca, en 1076, a instancias del obispo García Ramírez, infante de Aragón; Pamplona, bajo el pontificado de Pedro de Rodez o de Andruque (1083- 1115); y Roda, a finales del mismo siglo XI, después de que se consolidó con la incorporación de la sede del título de la antigua Lérida.

La catedral de Roda de Isábena (D’Abadal, 1970: 57-112; Del Arco, 1942: 233-235; Ducos, 1971: 175-300; Pladevall, 1974: 60; Rubio, 1960: 85-125; Ubieto, 1956-1957: 327-337; Yela, 1932; Zaragoza, 1997: 195) sucumbió al ser reconquistada esta ciudad de Lérida en 1149. Sin embargo, esto no atentó contra la vida regular en esta plaza hoy aragonesa. Al contrario. El obispo Guillerno Pedro, en 1168, reformó el cabildo según la Regla de san Agustín, obligó a los veinticinco canónigos a vestir hábito y a tomar posesión el día de la Virgen de agosto, y dejó instaurada otra canónica agustiniana, ya no catedralicia, en la mencionada Roda, dependiente ahora de la de Lérida. ${ }^{40}$

En San Andrés de Fanlo (Gómez de Valenzuela, 2001: 89-114; Establés,

Sobre la evolución de la sede catedralicia de Roda de Isábena, vid. De La Canal, 2006; Castillón, 2001-2003: 51-58; Gonzalo, 2008: 133-192; Gros, 2007: 339-356; Iglesias, 1987; Id., 1993: 287-320; Pesqué, 1995: 675-690; De Las Pueblas - Terrazos - Selfa, 2003: 747-758. Su documentación ha sido publicada hace unos años: Grau, 2010. 
2000: 4-6),$^{41}$ como en otros monasterios aragoneses, la propagación de la vida de los clérigos regulares fue en detrimento de la tradicional vida monástica. Este monasterio, según F. Balaguer (Balaguer, 1996: 233-244), fue uno de los más poderosos del Alto Aragón. Hoy ha desaparecido, pero existen noticias de su existencia ya en el año 958. Parece que el lugar no sufrió pérdidas irreparables durante los ataques de Almanzor y de su hijo Abd al Malik y, durante el abadiato de Banzo de Fanlo (1035- 1070), aumentó poderosamente su patrimonio, garantizado por la presencia del monarca Ramiro I como protector del cenobio.

Sin embargo, a la muerte Ramiro I, la reforma de Sancho Ramírez provocó que, entre 1071 y 1083, el monasterio del Salvador y San Andrés de Fanlo se agregara a la canónica regular agustiniana creada en el castillo de Loarre por el rey Sancho. Parece que, detrás de esta decisión estuvo la negativa de la comunidad a aceptar el rito romano que, desde la Reforma Gregoriana, venía imponiendo el rey aragonés, así como la aceptación de la Regla de san Agustín que conllevaba este cambio. En 1101, tanto Fanlo como Loarre quedaron unidos a Montearagón y, por tanto, reducidos a simples prioratos sin independencia jurídica ni administrativa.

Según los autores, en el castillo de Loarre hubo canónigos desde 1071 hasta que se trasladaron, en 1097, a la nueva sede de Montearagón por las maniobras del monarca Pedro I de Aragón y de Navarra. ${ }^{42}$ Hay indicios de que el propio abad de Fanlo pasó a gobernar Loarre, lo que no deja de ser un problema para los historiadores. Por un lado, un abad de un monasterio de monjes habría pasado a gobernar otro de canónigos regulares, al que se habría agregado su comunidad. Por otro, quizás más complicado aún de comprender, una comunidad benedictina habría suplantado su norma monacal por la de los canónigos de san Agustín, con su consiguiente cambio de condición religiosa.

A. Durán Gudiol ${ }^{43}$ afirmó que, especialmente en Aragón, la presencia benedictina llegó a ser insignificante ante la poderosa marcha de los canóni-

41 La documentación del monasterio fue editada por Ángel Canellas en 1963: Canellas, 1963: 281-448. En torno al Beato de Fanlo, también existen algunas monografías. Vid. Galtier, 2005. La documentación del monasterio ha sido editada hace algunos años: Laliena - Knibbs, 2007.

42 El castillo de Loarre ha sido ampliamente estudiado desde el punto de vista artístico e histórico. Los estudios sobre la vida del cabildo de canónigos regulares de esta plaza fortificada resultan, sin embargo, casi desconocidos: Vid. Del Arco, 1968: 5-37; Español, 2005-2006: 7-18; De La Figuera, 1924: 117-119; Gascón, 1968: 149-160; Durán, 1987: 23-26; Lampérez, 1901: 221-224; Martínez Prades, 2005. El trabajo interdisciplinar más importante sobre Loarre corresponde a: Guitart, 2004.

43 El mismo autor ha estudiado ampliamente la vida de la Iglesia aragonesa durante la Edad Media: Durán, 1961: 1-103; 1991: 69-88. 
gos regulares (Durán, 1962). A pesar de la imprecisión de las fuentes, en tal sentido parecieron ir ciertos casos de restauraciones monásticas de la monarquía aragonesa, de acuerdo a una aceptación compartida. Así sucedió en el concilio de Jaca del 1063, convocado por Ramiro I, en el que los nueve obispos que lo celebraron trasladaron allí la sede de Huesca, todavía por reconquistar, y decidieron fundar o restaurar los monasterios de Lierdi, Sietefontes, Ravaga, Santa María y San Pedro de Siresa. El monasterio de San Adrián de Sasave (Valenzuela, 1968: 283-296), hasta ahora refugio de los obispos de Huesca en el exilio, hacia 1050 había sido donado al obispo aragonés para dar paso a su restauración espiritual mediante la expulsión de una comunidad monástica relajada.

El hijo de Ramiro I, Sancho Ramírez, rey de Aragón desde 1063 a 1094 y de Navarra desde 1076, impulsó la repoblación de las zonas reconquistadas, pasando a ser el gran promotor de la vida canonical y de la norma agustiniana en su monarquía. Al avanzar la reconquista, se reservó la jurisdicción exenta de las iglesias que iban surgiendo en algunos lugares y las entregó a los también nuevos canónigos agustinianos como capillas reales. Ya hemos mencionado el caso del castillo de Loarre, pero también los de Alquézar, ${ }^{44}$ Montearagón y Monzón, además de los monasterios de Asán ${ }^{45}$ y Siresa (Del Arco, 1919: 270-305; Caballero - Esteban - García Guatas, 1989-1990: 241-296; Esteban, 1994-1995: 511-516; Puertas, 1993; Ubeira, 1999). ${ }^{46}$

En mayo de 1088, Sancho Ramírez inició la fortificación del altozano de Montearagón (Esco, 1987; Durán, 1987: 20-25) ${ }^{47}$ con el fin de apoyar una acción de guerra que condujera a la conquista de la ciudad de Huesca. En la primavera del año siguiente, el abad Frotardo se encontraba en Roma, donde ponderó los méritos del rey al papa Urbano II y obtuvo de él la bula Iusta

44 Sobre el cabildo de Alquézar, vid. Durán, 1990.

45 Sobre la antigüedad del monasterio de Asán, vid. Fortacín, 1983: 7-70.

46 El propio Antonio Durán elabora una aproximación histórica al monasterio de Siresa, iniciada en el año 851 con la carta que Eulogio de Córdoba envía al obispo Wilesindo de Pamplona dándole cuenta de la visita que había realizado a los monasterios de Leire, Ciellera, Siresa, Igal y Urdaspal. El monasterio carolingio de Siresa, fundado hacia el año 833, conserva una iglesia probablemente anterior al siglo XI, resultante de la destrucción de la anterior, hacia el año 999, con motivo de las razias del moro Almanzor, que se encontraba en pie cuando se confirma su adhesión a la Regla de san Agustín en 1082. Vid. Durán, 1991: 7-14.

47 Sobre este castillo monasterio y su documentación: Del Arco, 1998-2002: 37-49; Cabré, 1959: 249 258; Ciprés, 1998-2002: 37-49; Serrano - Mur, 2006: 363-409. Otros estudios, analizan aspectos concretos del lugar: Cárdena, 1993: 227-234; Cingolani, 2012: 39-66; Cobos, 2006: 91-124; Villacampa, 2000: 173-220. 
fidelium, del 1 de julio, por la que el pontífice puso bajo la protección de la Santa Sede el monasterio, el rey y sus reinos, y dictó normas sobre la elección del abad y sobre las relaciones con los obispos diocesanos.

Destaca sobre todo la sanción que hizo el papa por esta vía de la teoría de las capillas reales, de las que el rey pudo disponer a su arbitrio sin contar con los obispos diocesanos. Hasta 1093, en que se inició la construcción de la iglesia, la canónica no era más que un proyecto, una fortaleza erigida en el centro del valiato de Huesca, pero que el rey supo favorecer en atención a los privilegios que obtuvo para él el abad Frotardo. Con el tiempo, le fueron cedidas diferentes villas, monasterios, iglesias y toda suerte de privilegios y exenciones, junto con su proclamación como cabeza de una inicial congregación, que no llegó a consolidar, de la que pasaron a formar parte las canónicas de Loarre, Fanlo y Siresa, lo que provocó el despoblamiento de canónigos de Loarre, más proclives a la vida junto a la ciudad de Huesca, que facilitaba Montearagón. ${ }^{48}$

\section{Conclusión}

En conexión con la Reforma Gregoriana y las exhortaciones de san Pedro Damiani (1007- 1072), la Corona de Aragón experimentó en el siglo XI uno de los mayores movimientos de transformación y centralización de su historia. Como explicó el profesor Álvarez Gómez, el gran momento de los canónigos regulares en Aragón fue el siglo XII. Se impuso la vida comunitaria en la mayoría de los cabildos catedralicios y colegiatas de los territorios actuales de Cataluña y Aragón, y el rey aprovechó su influencia para consolidar algunas de sus posiciones en la esfera internacional.

Sin embargo, esta presencia más o menos extensa de la obra agustiniana en la Corona de Aragón no supuso tampoco una transformación radical

48 Antonio Linage Conde confirma, mediante las conclusiones de su estudio de la documentación de la catedral de Huesca, la voluntad organizadora y disciplinar de la corona de Aragón en la segunda mitad del siglo XI en la Iglesia regular y su recurso a la Regla de san Agustín. La Regla de san Benito y el monacato tradicional aparecían como exánimes y quedaban lejos para las aspiraciones de la mentalidad de quienes pretendían reformar desde el exterior unas fundaciones eclesiásticas necesitadas de vigor. El beneficio de este impulso reformador apenas puede documentarse para algunos casos concretos del viejo monacato benedictino, como el de la iglesia de San Pedro el Viejo, de Huesca, primera catedral de la sede, que fue donado por el obispo Pedro, con la aquiescencia de Pedro I y de la condesa doña Sancha, a la abadía de San Pontio de Thomiéres, donación que confirmó Pascual II en Troyes con fecha de 25 de mayo de 1107. Vid. Linage, 1982: 406-426. 
del clero. Antonio Linage y de Antonio García y García nos recordaron que, en estos territorios, la vida clerical regular no fue la ordinaria de los sacerdotes, sino un estado específico dentro de la Iglesia, resultado de la Reforma Gregoriana. Los canónigos regulares, aunque dijeron que eran una renovación de la primitiva vida apostólica, constituyeron una innovación y una nueva realidad al lado de los otros canónigos seculares y del monaquismo benedictino.

En la práctica, las dificultades fueron grandes, ya que la mayor parte de los sacerdotes rechazaron someterse a un ideal de vida tan exigente. No resultó fácil mantener la especificidad de la espiritualidad canónica, que se hizo patente con el paso de los años. Esta espiritualidad ejerció mayor influencia sobre los sacerdotes en la medida en que estableció la conexión entre el ideal sacerdotal y la práctica de la vida común, pero pronto tendió a hacerse insostenible, a acercarse a las conformaciones de los cabildos seculares de acuerdo a las disposiciones de Aquisgrán, o a asimilarse a la vida de los monjes, con la consiguiente degradación de significado para el cura rural o de las parroquias de las ciudades quienes, de nuevo, perdieron todo modelo de espiritualidad adaptado a su situación concreta y a su nivel cultural.

Donde fue aceptada la reforma se les empezó a llamar canónigos regulares, reservando el calificativo de irregulares o de seculares para aquellas comunidades que permanecieron adscritas a las formulaciones del orden antiguo, caracterizadas por los decretos de Aquisgrán. En algunas regiones aragonesas, la difusión de los canónigos regulares tuvo lugar únicamente como consecuencia de «conversiones» individuales de clérigos o de predicadores itinerantes en comunidades de clérigos, que abandonaban, por fervor, las instituciones tradicionales.

En ocasiones, algunos clérigos llegaron a fundar nuevos monasterios e iglesias rurales y urbanas que se yuxtapusieron a las colegiatas y cabildos seculares. En algunos casos, las comunidades adoptaron la vida canónica después de una experiencia eremítica más o menos prolongada. En otros, su origen se remontaba a grupos de penitentes que encontraron en este tipo de vida mayores facilidades para el ejercicio de su actividad caritativa. Un paradigma cercano fue el de los viejos cenobios hospitalarios, como los monasterios del Camino de Santiago, que adoptaron la nueva Regla como «liberación» de la vida monástica tradicional para una dedicación más apropiada a las tareas asistenciales. 
Desde los primeros años del siglo XII, todos estos monasterios, surgidos de la reforma, empezaron a vincularse con la Regla de san Agustín, lo que les valió el título de canonici sancti Augustini. Pero, con toda probabilidad, no todos le concedieron el mismo significado ni le otorgaron la misma validez. Según las tendencias, algunos monasterios, fundamentalmente los de origen eremítico, se emparentaron al más estricto ordo monasterii o regula secunda, que llevaba al ordo novus, como forma de vida muy severa, que ponía el acento tanto en el ascetismo (ayunos, silencio, sencillez en el vestido), como en el trabajo manual y en la pobreza, si bien el perfil genuino de cada comunidad lo determinaron las propias consuetudines, que ellos mismos redactaron.

En la práctica, la mayor parte de los canónigos regulares se contentó con cumplir la regula prima o praeceptum, que contenía la doctrina más suavizada del obispo de Hipona y que llevaba al ordo antiquus. En realidad, esta Regla era una carta de san Agustín en la cual describía la existencia cotidiana de la pequeña comunidad sacerdotal que vivía reagrupada en torno a él en un «monasterio de clérigos». Este texto recomendaba la moderación y subrayaba especialmente la vida en común sin propiedad privada.

A principios del siglo XIII, ante este movimiento centralizador y comunitario, suscitado por la Reforma Gregoriana surgió, como contrapartida, un cierto proyecto contrario, favorecido por obispos y abades partidarios de la propiedad privada. En poco tiempo, en algunos cabildos se establecieron dos mesas: una episcopal o abacial y otra capitular. Como en el resto de Europa, se inició la decadencia de la institución canonical. Otras formas de vida religiosa se hicieron presentes y compitieron con las instituciones monásticas y canonicales: las Órdenes mendicantes. Solamente en los siglos XIV y XV, se advirtió en la Corona de Aragón un breve resurgir de los canónigos regulares, también en las Islas Baleares y en los territorios de la Península Italiana, pero nunca con la misma fuerza que experimentaron en el siglo XII.

En todos estos casos, resulta complicado afirmar que estemos ante una reforma general del clero. Los nuevos monasterios respondieron mejor al esquema de una fundación de nuevo cuño que salió al paso de las nuevas circunstancias que demandó la vita apostolica de la baja Edad Media. Es decir, toda esta historia concierne más bien a la vitalidad de una Iglesia transformada que responde a una necesidad con una forma nueva de apostolado. La renovación del sacerdocio tradicional, según los datos que hemos manejado, tuvo que esperar todavía a tiempos mejores. 


\section{Referencias bibliográficas}

ÁLVAREZ DE LAS ASTURIAS, N. (ed.) (2011), La Reforma Gregoriana en Espa$\tilde{n} a$, Madrid.

ÁLVAREZ GÓMEZ, J. (1989), Historia de la vida religiosa II. Desde los canónigos regulares hasta las reformas del siglo XV, Madrid.

BALAGUER SÁNCHEZ, F. (1996), «Seis diplomas reales de Fanlo en San Pedro el Viejo de Huesca», Argensola, 110, 233-244.

BARAUT, C. (1978), «Les actes de consagració d'esglèsies del bisbat d'Urgell (segles IX-XII)», Urgellia, 1, 11-182.

- (1980), «El monestir de St. Sadurní de Tavérnoles i els orígenes del monaquisme benedictí al comtat d’Urgell», Studia monástica, 22, 253-259.

BENET I CLARÀ, A. (1994), Diplomatari de la ciudat de Manresa (s. IX-X), Manresa.

BENITO I MONCLÚS, P. (2004), «Entre la beneficencia y la `familiaritas`: la contratación del 'victum et vesitum' en los monasterios catalanes durante los siglos XIXII. Una respuesta institucional alternativa ante el hambre como problema social», Anuario de Estudios Medievales, 34, 3-30.

CABALLERO SUBIZA, B.- ESTEBAN LORENTE, J. F.- GARCÍA GUATAS, M. S. (1989- 1990), «Siresa: crónica de una restauración polémica», Artigrama: revista del Departamento de Historia del Arte de la Universidad de Zaragoza, 6- 7, 241296.

CABRÉ, M. D. (1959), «Cinco documentos del infante don Fernando, abad de Montearagón», Argensola, 39, 249-258.

CALLEJA PUERTA, J. (2009), «Los canónigos regulares en los reinos de León y Castilla», en GARCÍA DE CORTÁZAR Y RUIZ DE AGUIRRE, J. A. - TEJA, R. (coord), Entre el claustro y el mundo: canónigos regulares y monjes premonstratenses en la Edad Media, Aguilar de Campoo, 37-62.

CANELLAS, Á. (1963), «Colección diplomática de San Andrés de Fanlo (958- 1270), Cuadernos de historia Jerónimo Zurita, 14- 15, 281-448.

CÁRDENA GARCÍA, M. T. (1993) «La residencia de los canónigos de Montearagón en Huesca: restos escultóricos», Artigrama, 10, 227-234.

CASADES Y GRAMATXES, P. (1897), Lo Lluçanés. Excursió a dita comarca, Barcelona.

CASTILLÓN CORTADA, F. (2001-2003), «El episcopologio de Roda de Isábena», Aragonia sacra: revista de investigación, 16- 17, 51-58.

CINGOLANI, S. M. (2012), «Fernando, abad de Montearagón, y Fernando Sánchez, hijos de Jaime I, y el monasterio de Santes Creus», Aragón en la Edad Media, 23, 39-66.

CIPRÉS SUSÍN, A. (1998-2002), «El castillo de Montearagón o real casa de Montearagón», Argensola, 112, 37-49. 
COBOS GUERRA, F. (2006), «Avance de los estudios sobre el castillo convento de Montearagón», en AAVV., Simposio internacional sobre arquitectura fortificada: conservación, restauración y uso de los castillos, Segovia, 91-124.

CONSTABLE, G. (1982), «Monasteries, rural churches and the cura animarum in the Early Middle Ages», en AAVV., Cristianizzazione ed organizzazione ecclesiastica delle campagne nell'Alto Medioevo: espansione e resistenze I, Spoleto, 349-389.

CORREDERA, E. (1978), El archivo de Áger y Caresmar, Balaguer.

CORTS PEYRET, J. (1953), Historia de la Seo de Urgel, Barcelona.

COSTA Y BAFARULL, D. (1959), Memorias de la ciudad de Solsona y su iglesia, Barcelona.

D’ABADAL I VINIALS, R. (1970), «Origen y procés de consolidació de la seu ribagorçiana de Roda», en VVAA., Dels visigots als catalans II, Barcelona, 57-112.

DANÉS I VERDERAS, J. (1912), La vall i el monestir de St. Joan de les Abadesses, Barcelona 1912.

DE LA FIGUERA Y LEZCANO, L. (1924), «El castillo de Loarre», Arquitectura: órgano de la Sociedad Central de Arquitectos, 60, 117-119.

DEL ARCO Y GARAY, R. (1919), «El real monasterio de Siresa, capilla real de Aragón», Boletín de la Sociedad Española de Excursiones, 27, 270-305.

- (1942), «Roda de Isábena», en VVAA., Catálogo monumental de la provincia de Huesca, Madrid, 233-235.

- (1968), «El castillo abadía de Loarre», Seminario de Arte Aragonés, 13- 15, 5-37.

- (1998-2002), «El monasterio de Montearagón», Argensola, 112, 37- 49.

DEREINE, C. (1946), «Vie commune. Règle de saint Augustin et chanoines réguliers au XIe siècle», Revue d'historie ecclésiastique, 41, 362-406.

- (1947), «Les origines de Prémontré», Revue d'Historie ecclésiastique, 42, 352-378.

- (1951), «L'Elaboration du statut canoniqe des chanoines réguliers spécialement sous Urban II», Revue d'Histoire Eclésiastique, 46, 534-565.

- (1961), «La prétendue réglé de Gregorie VII pour chanoines réguliers», Revue Bénédictine, 71, 108-118.

- (1971), «Chanoines», en VVAA., Dictionnaire d'histoire et de géographie ecclésiastiques, t. XII, París, 383.

DUCOS, J. (1971), «Roda de Isábena. Un diocèce espagnol des Pyrénees Centrales», Ilerda, 32, 175-300.

DURÁN GUDIOL, A. (1961), «Geografía medieval de los obispados de Jaca y Huesca», Argensola, 45-46, 1-103.

- (1962), La Iglesia de Aragón durante los reinados de Sancho Ramírez y Pedro I (1062?-1104), Roma.

- (1987), El castillo abadía de Montearagón (siglos XII y XIII), Zaragoza.

- (1990), La villa y la colegiata de Alquézar, Huesa.

- (1991), «Dos cuestiones sobre el monasterio de San Pedro de Siresa», Príncipe de Viana, 52, 7-14. 
DURÁN GUDIOL, A. (1991), «Monasterios y monasteriolos en los obispados de Pamplona y Aragón en el siglo XI», Príncipe de Viana, 193, 69-88.

- ( $\left.{ }^{2} 1987\right)$, El castillo de Loarre y sus alrededores, Zaragoza.

ESCO SAMPÉRIZ, C. (1987), El monasterio de Montearagón en el siglo XIII: poder político y dominios eclesiásticos en el Alto Aragón, Huesca.

ESPAÑOL BERTRÁN, F. (2005-2006), «El castillo de Loarre y su portada románica», Locus amoenus, 8, 7-18.

ESTABLÉS ELDUQUE, J. M. (2000), «Mil años de historia de los valles de Serrablo y Fanlo (958-1958)», Serrablo 117, 4-6.

ESTEBAN LORENTE, J. F. (1994-1995), «El laberinto de la iglesia de San Pedro de Siresa», Artigrama, 11, 511-516.

FERRANDO I ROIG, A. (1987), El monastir de Sant Llorenç del Munt i les seves possessions, Motserrat.

FITE LLEVOT, F. (1985), Reculls d'història de la Vall d'Àger. Període antic i medieval, Àger.

FORTACÍN PIEDRAFITA, J. (1983), «La donación del diácono Vicente al monasterio de Asán y su posterior testamento como obispo de Huesca en el siglo VI: precisiones críticas para la fijación del texto», Cuadernos de historia Jerónimo Zurita, 47-48, 7-70.

FRANCINO PINASA, G. (2003), «Topònims ribagorçans al cartoral del monestir de Lavaix, durant els s. XI- XIII», Societat d'Onomàstica: bulletí interior, 93, 545562.

GALTIER MARTÍN, F. (2005), El beato del abad Banzo del monasterio de San Andrés de Fanlo, un apocalipsis aragonés recuperado, Zaragoza.

GARCÍA DE CORTÁZAR Y RUIZ DE AGUIRRE, J. A. - TEJA, R. (2009) (coord), Entre el claustro y el mundo: canónigos regulares y monjes premonstratenses en la Edad Media, Aguilar de Campoo.

GASCÓN DE GOTOR, A. (1968), «El castillo roquero de Loarre», Castillos de España: publicación de la Asociación Española de Amigos de los Castillos, 61, 149160.

GASOL, J. M. (1978), La seu de Manresa. Monografia històrica i guia descriptiva, Manresa.

GIMENO BLAY, F. M. (1992), «Consideraciones acerca de la datación de un `membrum disiectum’ procedente del monasterio de Lavaix», Medievalia, 10, 169-192.

GIROURD, C. (1961), L’ordre des chanoines réguliers de saint-Augustin et ses diverses formes de régime interne. Essai de synthèse historico-juridique, Martigny.

GOLOBARDES VILA, M. (1949), El monasterio de Santa María de Vilabertrán, Barcelona, 1949.

GÓMEZ DE VALENZUELA, M. (2001), «Los señoríos de Arruba y de Fanlo en el Serrablo: datos históricos y genealógicos», Emblamata: Revista aragonesa de emblemática, 7, 89-114. 
GÓMEZ SANTOS, A. (1971), «Santa María de Párraces, Nuestra Señora de la Sierra y San Pedro de los Picos», Estudios segovianos, 68-69, 301-316.

GONZALO LÓPEZ, J. (2008), «Suerte de noticias, principalmente sobre el órgano, extraídas del archivo de la catedral de Roda de Isábena (Huesca) y datación e inventario de todas las partes del instrumento», Nassarre: Revista aragonesa de musicología, 24, 133-192.

GRAU QUIROGA, N. (2010), Roda de Isábena en los siglos X-XIII. La documentación episcopal y el cabildo catedralicio, Zaragoza.

GROS I PUJOL, M. DELS S. (2007), «L'inventari de l'antiga biblioteca de la catedral de Roda d'Isàvena», Revista catalana de Teología, 32, 339-356.

GUERRERO URIARTE, A. (1971), St. Pere de Grau d'Escales en el valle de Lord, Ilerda.

GUITART APARICIO, C. (2004), El castillo de Loarre, León.

IGLESIAS COSTA, M. (1987), Roda de Isábena, ex sede y catedral ribagorzana, Huesca.

- (1993), «El cartulario de Roda según Abad y Lasierra», Argensola, 107, 287-320.

LALIENA CORBERA, C.- KNIBBS, E. (2007), El cartulario del monasterio aragonés de San Andrés de Fanlo (siglos X-XIII), Zaragoza.

LAMPÉREZ Y ROMEA, M. (1901), «La iglesia de Santa María en el castillo de Loarre», Boletín de la Sociedad Española de Excursiones, 9, 221-224.

LINAGE CONDE, A. (1982), «Reorganización de la vida común del clero. Canónigos regulares. Premonstratenses», en R. GARCÍA VILLOSLADA, (dir) Historia de la Iglesia en España II-1. La Iglesia en la España de los siglos VIII- XIV, Madrid, 406-426.

LLEDÓS I MIR, M. (1977), Historia de la antigua villa hoy ciudad de Tremp, Barcelona.

LLOBER I PORTELLA, J. M. (1990), «Un llibre de poesies, fins ara desconegut, del canonge Jeroni Ferrar de Guissona (1634)», Ilerda, 48, 229-236.

MARQUÉS PLANAGUMÁ, J. M. (2006), «La Iglesia de Gerona», en J. M. MARTÍ BONET (coord.), Historia de las diócesis españolas 2, Barcelona, Terrassa, Sant Feliu de Llobregat, Gerona, Madrid, 461-683.

MARTÍ BONET, J. M. (1981), Catàleg monumental de l'arquebisbat de Barcelona. Vallès Oriental, Barcelona.

MARTÍNEZ PRADES, J. M. (2005), El castillo de Loarre: historia constructiva y valoración artística, Huesca.

MARTÍNEZ, F. (1967), Sant Jaume de Frontanyá. Mil anys d'història i geografia, Granollers.

MIR I AMAT, J. (1978), Tremp al pas del temps, Tarragona.

MONSALVATJE Y FOSSAS, F. (1910), El monasterio de San Pedro de Casserras, Gerona.

MUNDÓ, A. (1961), «El políptic dels béns i censos de St. Pere de Vilamajor», Boletín del archivo histórico y museo Fidel Fita, d'Arenys de Mar, 9, 48-67. 
PARISSE, M. (ed.) (2009), Les chanoines réguliers. Émergence et expansion (xieXIIIe siècles), Saint-Étienne.

PASCUAL, J. (1785), Disertación sobre el obispado de Pallars, Barcelona.

PESQUÉ LECINA, J. M. (1995), «Documentos del priorato de Roda: siglos XI al XX», en VVAA., Homenaje a don Antonio Durán Gudiol, Huesca, 675-690.

PLADEVALL, A. (1969), El monestir de Sta. Maria de Lluçà, Granollers.

- (1974), Els monestirs catalans, Vitoria.

- (1978), El monestir romànic de Santa Maria de l'Estany, Barcelona.

- (1982), El monestir de Sant Sebastià dels Gorgs, Barcelona.

- (1994), «Institucions i organització. Les institucions i organització de l'eglésia catalana», Analecta sacra tarraconensia: revista de ciències historicoeclesiàstiques, 67, 181-196.

- (2001), «Sant Segimon, el més importan Santuari del Montseny, ara en curs de restauració», Monorafies del Montseny, 16, 59-72

- (2002), «El benefici de Santa Maria de Piugdot de l'eglésia de Sant Martí de Viladrau», Monografies del Montseny 17, 145-154.

PLADEVALL, A.- ADELL, J. A. (1980), El monastir de Sant Llorenç del Munt, Barcelona.

PONS GURI, J. M. (1984), Cartoral de Santa Maria de Roca Rossa, Barcelona.

PUEBLAS, J. M.- TERRAZOS CEPEDA, F. J.- SELFA I SASTRE, M. (2003), «La importància de la documentació de Roda d'Isàvena per a la història de les llengües i de l'onomàstica dels Pirineus», Societat d'Onomàstica: bulletí interior, 93, 747 758.

PUERTAS TRICAS, R. (1993), Excavaciones en San Pedro de Siresa, Huesca.

PUIG I CADAFALCH, J. (1918), L'arquitectura romànica a Catalunya II, Barcelona.

PUIG I FERRETÉ, I. (1984), El cartoral de Santa María de Lavaix: El monastir durant els segles XI-XIII, Seu d'Urgell.

RIU RIU, M. (1970-1971), «El monaquismo en Cataluña en el siglo XIV», Anuario de Estudios Medievales, 7, 593-614.

- (1977), El monasterio de Santa María de Labaig o Lavaix, Silos.

- (1978), «Les rendes dels monestirs i de les canòniques del bisbar d’Urgell», Urgellia, 1, 267-290.

- (1979), «La canònica de Santa María de Solsona. Precedents medievals d’un bisbat modern», Urgellia, 2, 211-256.

- (1982) «El monestir de St. Llorenç de Morunys als segles X i XI», Urgellia, 5, 159-182.

- (1988), «Monacato y colonización rural en la Cataluña altomedieval», Codex aquilarensis: cuadernos de investigación del Monasterio de Santa María la Real,2, 85-112.

- (1990-1991), «Documents del Archivo Histórico Nacional de Madrid referents a monestirs i canòniques del Bisbat d’Urgell (segles XII-XV)», Urgellia, 10, 351-373. 
ROIG I JALPÍ, J. G. (1688), Tratado de las excelencias de Santa María de Meyá, Barcelona.

- (1676), Resumen historial de las grandezas y antigüedades de la ciudad de Gerona, Barcelona.

RUBIO GARCÍA, L. (1960), «Problemas y cuestiones de la sede de Roda hasta su traslado a Lérida», Ilerda, 24, 85-125.

SANAHUJA, P. (1961), Historia de la villa de Áger, Barcelona.

SANGÉS, D. (1980), «Recull de documents del segle XI referents a Guissona i la seva plana», Urgellia, 3, 195-305.

- (2006-2007), «Els documents del segle XIII (1201-1225) del fons de Guissona, conservats a l’Arxiu diocesà d’Urgell», Urgellia, 16, 171-334.

SARRET I ARBÓS, J. (1924), Història religiosa de Manresa: esglésies i convents, Manresa.

- (1954), El castell de Cardona, Cardona.

SASTRE SANTOS, E. (1983), «Notas bibliográficas sobre los canónigos regulares», Hispania sacra, 35, 251- 314.

SERRA Y VILARÓ, J. (1916), Pretiosa sive caputbrevium monasterii castri cardonensi, Barcelona.

- (1950), Les baronies de Pinós i Mataplana, Barcelona.

SERRANO LARRAYOZ, F.- MUR SANGRÁ, L. (2006), «Documentación sobre el monasterio de Montearagón conservada en la sección de Comptos del Archivo General de Navarra (1205- 1454)», Argensola, 116, 363-409.

SOLÀ, F. (1964), Història de Sant Llorenç del Munt, Sabadell.

TORRENT Y GARRIGA, D. (1893), Manlleu. Croquis para su historia, Vic.

TRISTANY BOFIL I BENAC, B. (1677), Corona benedictina, Barcelona.

UBEIRA HERNÁNDEZ, J. L. (1999), Siresa: el lugar, la historia, la leyenda, Huesca.

UBIETO ARTETA, A. (1956-1957), «El origen ilerdense de la sede de Roda», Ilerda, 20-21, 327-337.

VALENZUELA MUÑOZ, J. M. (1968), «San Adrián de Sasave», Actas del quinto congreso internacional de estudios pirenaicos: Jaca-Pamplona 1966, San Sebastián, 283-296.

VAYREDA I OLIVAS, P. (1931), El priorat de Lladó i les seves filials, Barcelona.

VERGÉS, A. (1871), Sant Llorenç del Munt: son passat, son present i porvir, Barcelona.

VILLACAMPA SANVICENTE, S. (2000), «El retablo de Montearagón en el Museo Diocesano de Huesca: estudio e informe tras su restauración (2001)», Aragonia sacra: Revista de investigación, 15, 173-220.

VILLANUEVA, J. L. (1850), Viage literario a las iglesias de España XII, Madrid.

VINYETA, R. (1978), Sant Jaume de Frontanyà i l'alta vall del riu Merlès, Torelló.

VVAA. (1962), La vita comune del clero nei secoli XI e XII. Atti della settimana di studio della Mendola, 2 vols. Milán. 
VVAA. (1991), La Orden del Santo Sepulcro. I Jornadas de estudio, Calatayud- Zaragoza-Madrid.

VVAA. (2006), La Reforma Gregoriana y su proyección en la cristiandad occidental: siglo XI- XII. XXXII Semana de Estudios Medievales. Estella, 18 a 22 de julio de 2005, Pamplona.

YELA UTRILLA, J. F. (1932), El cartulario de Roda, Lleida.

ZARAGOZA PASCUAL, E. (1977), «Documentos inéditos referentes a la reforma monástica en Cataluña durante la segunda mitad del siglo XVI (1555-1600)», Studia monástica, 19, 93-203.

- (1987), «Catálogo de los prelados de Santa María de Meyá», Analecta sacra Tarraconensia, 60, 281-290.

- (1996), «Los monasterios de canónigos regulares de san Agustín en Cataluña», Revista agustiniana, 37, 661-721.

- (1997), Catàleg dels monestirs catalans, Barcelona. 